\title{
CAULINITA TRATADA COM ÁCIDO FOSFÓRICO E INTERCALADA COM ACETATO DE POTÁSSIO
}

\author{
A. PRASNIEWSKI ${ }^{1}$, J. C. K. NEVES ${ }^{2}$, C. R. BUDZIAK-PARABOCZ ${ }^{1}$ \\ ${ }^{1}$ Universidade Tecnológica Federal do Paraná, campus Pato Branco, Dep. de Química \\ ${ }^{2}$ Universidade Tecnológica Federal do Paraná, campus Curitiba, Dep. de Mecânica \\ E-mail para contato: anaclaraprasniewski@hotmail.com
}

\begin{abstract}
RESUMO- Os argilominerais possuem estruturas lamelares, e por isso são muito estudados nos processos de intercalação de moléculas orgânicas visando a melhoria de suas propriedades. Portanto, foram tratadas oito amostras de caulinita com $\mathrm{H}_{3} \mathrm{PO}_{4}$ em $5 \mathrm{~mol} / \mathrm{L}$ e $10 \mathrm{~mol} / \mathrm{L}$ para aumento de porosidade, após, a caulinita tratada foi submetida a intercalação com acetato de potássio $\left(\mathrm{CH}_{3} \mathrm{COOK}\right) \mathrm{em}$ diferentes proporções. As amostras foram caracterizadas a partir de análises de espectroscopia de infravermelho com transformada de Fourier (IV-TF) e o índice de intercalação e a distância lamelar foram calculados através de análise dos difratogramas de raios X (DRX). As amostras com $5 \mathrm{~mol} / \mathrm{L}$ de $\mathrm{H}_{3} \mathrm{PO}_{4}$ à $20 \%$ e $30 \%$ de $\mathrm{CH}_{3} \mathrm{COOK}$ obtiveram os melhores índices de intercalação $91,06 \%$ e $95,25 \%$ respectivamente. Foi observado que intercalações acima de $60 \%$ obtiveram aumento na distância lamelar de $6,85 \AA$ quando comparado com a caulinita pura. Para todas as amostras os espectros de infravermelho apresentaram picos característicos de $\mathrm{OH}$ ligados na camada interna da caulinita na região de 3600 - $3700 \mathrm{~cm}^{-1}$. E ainda, uma banda de $1400 \mathrm{~cm}^{-1}$ foi observada para estiramento $\mathrm{C}=\mathrm{O}\left(\mathrm{COO}^{-}\right)$indicando presença do acetato de potássio nas amostras, confirmando a intercalação.
\end{abstract}

\section{INTRODUÇÃO}

A caulinita é um argilomineral de alumínio com composição química $\mathrm{Al}_{2} \mathrm{Si}_{2} \mathrm{O}_{5}(\mathrm{OH})_{4}$, é uma dioctaédrica 1: 1 (CHENG, et al, 2010). Possui grande aplicabilidade na indústria, se ordena de forma foliar facilitando assim a alteração de sua composição. De um lado da lamela, a caulinita possui átomos de alumínio ligados à hidroxila octaédricamente, já na outra lamela há sílica coordenada na forma tetraédrica (GARDOLINSKI, et al, 2001). As interações interlamelares ocorrem através de ligações de hidrogênio, essa característica colabora para que a caulinita seja muito utilizada para intercalação, pois, através das fortes ligações de hidrogênio podem-se imobilizar muitos compostos orgânicos (GARDOLINSKI, et al, 1999). Devido às propriedades físico-químicas conhecidas, a caulinita vem sendo cada dia mais pesquisada e, uma das formas mais estudadas de manipulação do composto é através de suas propriedades de intercalação.

$\mathrm{O}$ acetato de potássio $\left(\mathrm{CH}_{3} \mathrm{COOK}\right)$ é um composto orgânico que pode ser usado como fonte de intercalação. Ele pode ser imobilizado nas lamelas através de reação de substituição com inserção indireta das moléculas orgânicas, fazendo com que aumente a distância interlamelar do material, melhorando assim suas propriedades (GUERRA, et al, 2008). 
A fim de melhorar as características dos argilominerais o tratamento com ácido inorgânico melhora as características do mineral quando comparado com o mesmo sem tratamento, pois elimina impurezas do material e colabora para o aumento da sua porosidade e da sua superfície específica, ajudando a minimizar a lixiviação do metal ativo (PANDA, et al, 2010; BELVER, et al, 2002).

Tendo em vista os fatores apresentados, o presente estudo traz a intercalação de fontes de potássio provenientes de $\mathrm{CH}_{3} \mathrm{COOK}$ em caulinita, tratada com ácido fosfórico. Caulinita submetida a diferentes tratamentos com $\mathrm{CH}_{3} \mathrm{COOK}$ e $\mathrm{H}_{3} \mathrm{PO}_{4}$ foi submetida à caracterização por Espectroscopia de Infravermelho com Transformada de Fourier (IV-TF) e quantificação de material intercalado com auxilio de Difratometria de Raios - X (DRX). Segundo Fernandes e Da Silva (2014) é crescente o interesse da indústria no potencial adsorvente e catalisador desse argilomineral, que posteriormente é difundido em diversas áreas cientificas e industriais.

\section{MATERIAIS E MÉTODOS}

\subsection{Tratamento de Caulinita com Ácido Fosfórico}

Foram tratadas oito amostras de caulinita com ácido fosfórico, em quatro delas foram adicionados $200 \mathrm{~mL}$ de $\mathrm{H}_{3} \mathrm{PO}_{4} 5 \mathrm{~mol} / \mathrm{L}$, e nas demais foram adicionados $200 \mathrm{~mL}$ de $\mathrm{H}_{3} \mathrm{PO}_{4} 10$ $\mathrm{mol} / \mathrm{L}$. O preparo da caulinita com ácido fosfórico ocorreu em condensador de refluxo por $3 \mathrm{~h}$ a $110^{\circ} \mathrm{C}$ e a reação foi interrompida com banho de água gelada, em seguida a amostra foi filtrada, lavada e seca em estufa a $100^{\circ} \mathrm{C}$ por $12 \mathrm{~h}$.

\subsection{Processo de Intercalação}

O processo de intercalação foi realizado utilizando $20 \mathrm{~mL}$ das concentrações $20 \%$, $30 \%, 31,4 \%$ e $47,1 \%$ em massa de $\mathrm{CH}_{3} \mathrm{COOK}$ para $10 \mathrm{~g}$ de caulinita tratada com $\mathrm{H}_{3} \mathrm{PO}_{4}$. As amostras foram colocadas sob agitação pelo período de $2 \mathrm{~h}$ e em seguida colocadas para secar a temperatura ambiente. As amostras foram preparadas a partir de caulinita proveniente do Rio Capim - $\mathrm{PA}, \mathrm{H}_{3} \mathrm{PO}_{4} 85 \%$ e $\mathrm{CH}_{3} \mathrm{COOK}$. As amostras foram submetidas a análises de DRX e Infravermelho para caracterização.

\subsection{Espectroscopia de Infravermelho com Transformada de Fourier (IV- TF)}

Pastilhas foram preparadas para análise utilizando $\mathrm{KBr}$ e amostra, a granulometria foi diminuída com auxilio de gral e pistilo. As análises foram realizadas em espectrômetro de infravermelho da marca Perkin Elmer, modelo Frontier, método de transmitância na faixa compreendida entre 400 a $4000 \mathrm{~cm}^{-1}$ utilizando-se de uma resolução de $4 \mathrm{~cm}^{-1} \mathrm{com}$ um número de acumulações de 32 varreduras para cada espectro. A análise por infravermelho possibilita a identificação das funções orgânicas da molécula, através do espectro gerado, onde também, o espectro de infravermelho serve para identificar o movimento vibracional presente nas moléculas.

\subsection{Difratometria de Raios $X(D R X)$}


A análise de DRX consiste na incidência de radiação em uma amostra e na detecção dos fótons difratados, que constituem o feixe difratado. As oito amostras foram analisadas em Difratômetro de raios X, Shimadzu 7000, com fonte de $\mathrm{CuK} \alpha(\lambda=1,54 \AA)$, e passo 0,020.

\section{RESULTADOS E DISCUSSÃO}

Com o auxilio da equação 1, foi possível determinar o índice de reação (IR) da intercalação, analisando os valores de intensidade do pico do intercalado $\left(\mathrm{Ii}_{(001)}\right)$ e intensidade do pico de caulinita $\left(\mathrm{Ik}_{(001)}\right)$.

$$
I R=\left(I i_{(001)} /\left(I k_{(001)}+I i_{(001)}\right)\right) x 100 \%
$$

Para os cálculos da distância lamelar foi utilizada a Lei de Bragg (Equação 2), onde d é a distância lamelar, $\lambda$ o comprimento de onda da fonte do feixe de raios-X incidente e $n$ é um número inteiro.

$$
2 d \operatorname{sen} \theta=n \lambda
$$

Tabela 1 - Índice de reação e distância lamelar para intercalação de potássio em

\begin{tabular}{|c|c|c|c|c|c|c|}
\hline Amostra & $\begin{array}{c}\text { Concentração } \\
\mathrm{H}_{3} \mathrm{PO}_{4}(\mathrm{Mol})\end{array}$ & $\begin{array}{l}\text { Porcentagem } \\
\text { de Acetato de } \\
\text { potássio }(\%)\end{array}$ & $\begin{array}{l}\text { Índice de } \\
\text { reação } \\
(\%)\end{array}$ & $\begin{array}{l}\text { Caulinit } \\
\qquad \begin{array}{l}\text { a } \\
\text { d } / \AA\end{array}\end{array}$ & $\begin{array}{l}\text { Caulinita e } \\
\mathrm{CH}_{3} \mathrm{COOK} \\
\text { intercalado } \mathrm{d} / \AA\end{array}$ & $\begin{array}{c}\text { Variação da } \\
\text { Distância lamelar } \\
(\AA)\end{array}$ \\
\hline 1 & 5 & 31,4 & 68,14 & 7,16 & 14,01 & 6,85 \\
\hline 2 & 5 & 47,1 & 21,82 & 7,16 & 11,96 & 4,80 \\
\hline 3 & 10 & 31,4 & 82,41 & 7,16 & 14,01 & 6,85 \\
\hline 4 & 10 & 47,1 & 58,15 & 7,2 & 11,96 & 4,75 \\
\hline 5 & 5 & 20 & 91,06 & 7,16 & 14,17 & 7,01 \\
\hline 6 & 5 & 30 & 95,25 & 7,16 & 14,01 & 6,85 \\
\hline 7 & 10 & 20 & 76,10 & 7,16 & 14,01 & 6,85 \\
\hline 8 & 10 & 30 & 81,81 & 7,16 & 14,01 & 6,85 \\
\hline $\begin{array}{c}\text { Caulinita } \\
\text { pura }\end{array}$ & - & - & - & 7,16 & - & - \\
\hline
\end{tabular}
caulinita. 
Com o auxílio das Equações 1 e 2, juntamente com a análise da Figura 1, foi possível calcular a porcentagem de intercalação para cada amostra e sua respectiva variação na distância lamelar indicada na Tabela 1. E ainda, a Tabela 1 evidencia os diferentes tratamentos de $\mathrm{H}_{3} \mathrm{PO}_{4}$ e $\mathrm{CH}_{3} \mathrm{COOK}$ para cada amostra e as distâncias lamelares para caulinita intercalada e caulinita pura.

Analisando a Tabela 1, pode-se notar que as amostra 5 e 6 apresentaram maior índice de intercalação 91,06 e 95,25\% respectivamente. Observou-se também, que para as amostras que tiveram um aumento na distância interlamelar de $6,85 \AA$ foi evidenciado mais de $60 \%$ de intercalação. Como esperado, os valores de distância lamelar do material intercalado são maiores que os do material sem tratamento Figura 1 (Caulinita pura), isso ocorre, pois, a intercalação promoverá mais espaçamento entre as lamelas, como demonstra a variação da distância lamelar, tornando visível o aumento do espaçamento após a reação de intercalação.

Figura 1 - DRX das amostras 1 - 8 e caulinita sem tratamento.

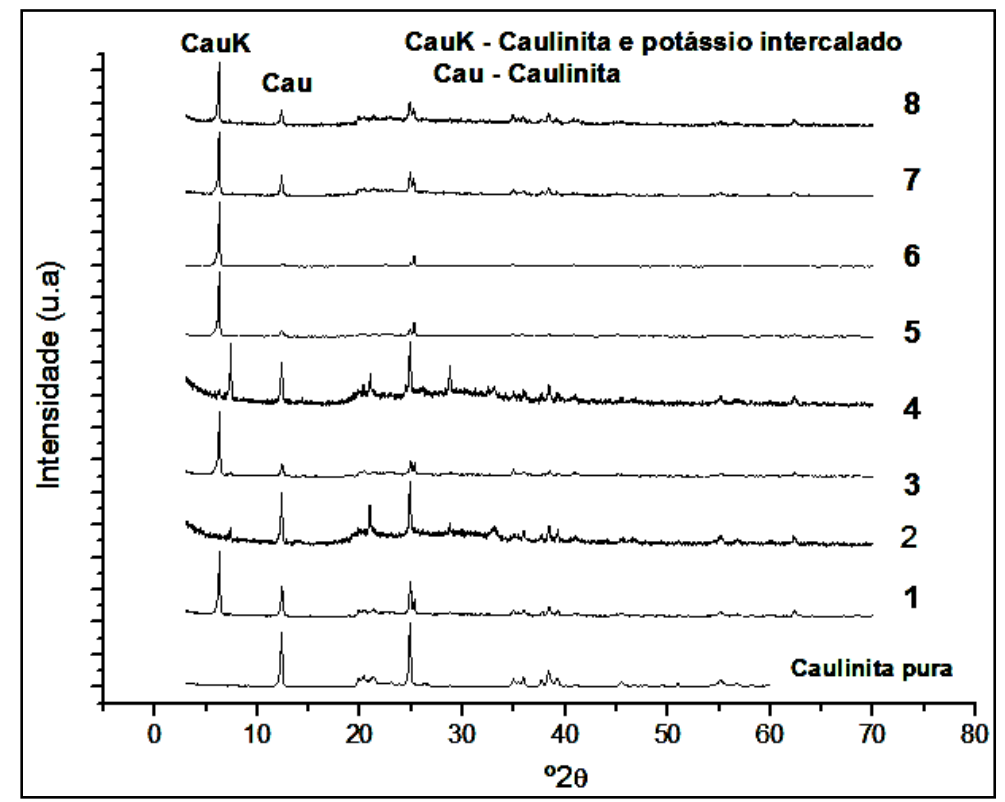

Ao analisar a Figura 2, pode-se notar que na região de $3600-3700 \mathrm{~cm}^{-1}$ há bandas características para moléculas de caulinita, pois os $\mathrm{OH}^{-}$livres localizados na camada interna são evidenciados nessa região do espectro. A banda em $3700 \mathrm{~cm}^{-1}$ evidencia as vibrações de estiramento de grupos $\mathrm{OH}^{-}$que estão ligados ao plano basal. Estes picos podem ser encontrados em todas as oito amostras intercaladas (Figura 3), porém, em menor intensidade. Há ainda em todos os espectros da Figura 3, com exceção das amostras 2 e 4, uma banda na região de $\sim 1600 \mathrm{~cm}^{-1}$ referente a molécula $\mathrm{H}_{2} \mathrm{O}$. E as bandas na região de $\sim 1000 \mathrm{~cm}^{-1}$ são características de estiramento (Si-O-Si). Ainda, o pico em $909 \mathrm{~cm}^{-1}$ refere-se à $\mathrm{OH}^{-}$ligados na camada interna. Couceiro e Santana (1999) evidenciaram em seus estudos espectros na mesma região, porém com duas bandas $\left(938\right.$ e $\left.914 \mathrm{~cm}^{-1}\right)$ referentes a hidroxila ligada na camada interna de caulinita, esta diferença relatada nos espectros pode provir da diminuição dos $\mathrm{OH}^{-}$ligados na camada interna com o aumento do intercalado, visto que, eles realizaram seus estudos com caulinita pura e, ou ainda provir da origem da caulinita. Na região de 1380 
$\mathrm{cm}^{-1}$ ocorrem deformação $\mathrm{CH}$ de $\mathrm{CH} 3$ e estiramento $\mathrm{C}=\mathrm{O}\left(\mathrm{COO}^{-}\right)$, essa banda é observada em todos os espectros das amostras intercaladas Figura 2 com um pequeno deslocamento em $1400 \mathrm{~cm}^{-1}$, essa vibração molecular constata a presença de acetato de potássio na amostra, visto que à Figura 2 não apresenta essa banda de vibração molecular.

Figura 2 - IV-TF Caulinita pura.

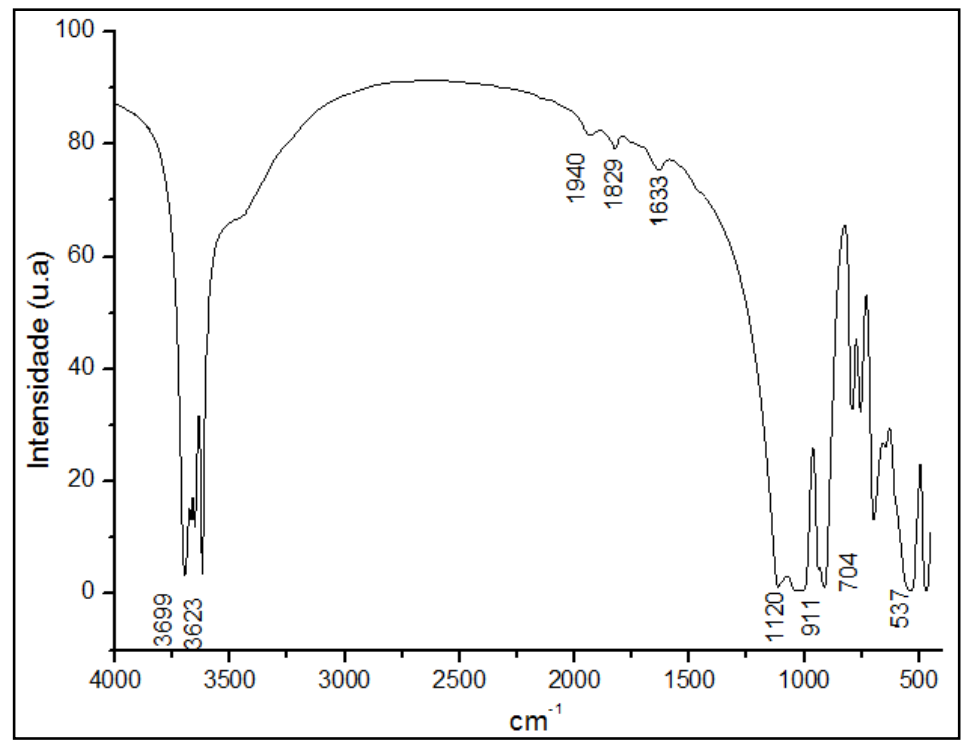

Figura 3 - IV-TF amostras 1 a 8.

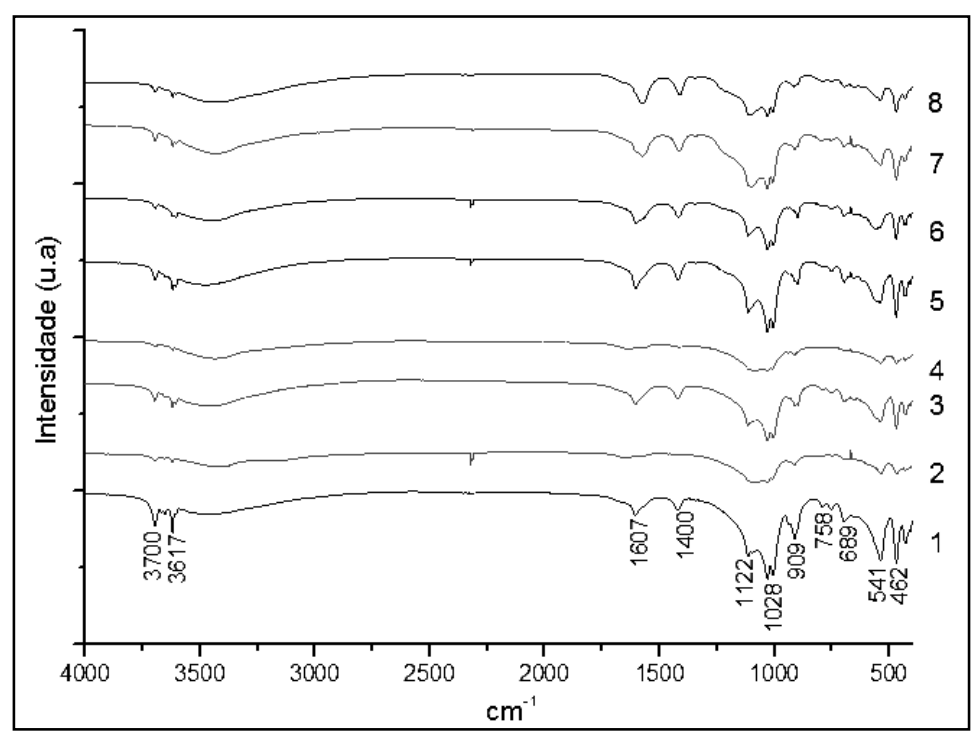

\section{CONSIDERAÇÕES FINAIS}

O método de intercalação mostrou-se efetivo, visto que, foi possível através da interpretação dos espectros de IV-TF constatar a presença de acetato de potássio nas amostras 


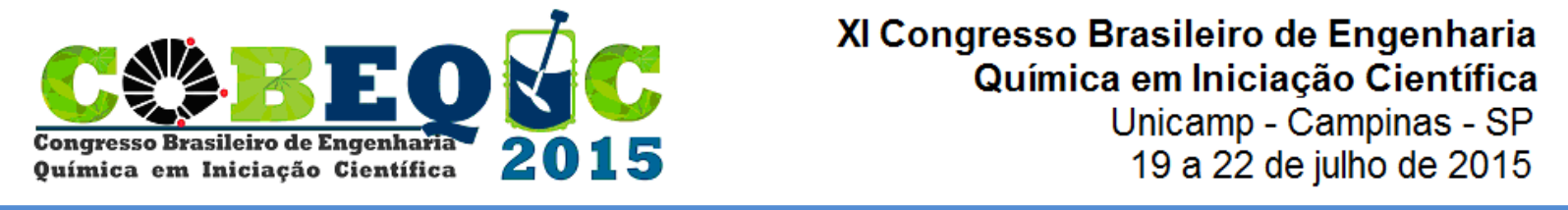

e os difratogramas de raios X mostraram a eficiência do processo de intercalação no material obtido.

\section{REFERÊNCIAS}

BELVER, Carolina; MUÑOZ, Miguel A. B.; VICENTE, Miguel A. Chemical Activation of a Kaolinite under Acid and Alkaline Conditions. Chem. Mater. 2002, vol.14, pp. 2033-2043.

CHENG, Hongfei; LIU, Qinfu; YANG, Jing; DU, Xiaoman; FROST, Ray L. Influencing factors on kaolinite-potassium acetate intercalation complexes. Applied Clay Science. 2010, vol.50, pp. 476-480.

COUCEIRO, Paulo R. C.; SANTANA, Genilson P. Caulinita em solo da Amazônia: caracterização e permutabilidade. Acta Amazonica. 1999, vol. 25, n.2, pp. 267-275.

FERNANDES, M. V. S.; DA SILVA, L. R. D. Síntese e caracterização de vermiculita mesoporosa obtida por modificação com sais complexos de alumínio e lantânio. Cerâmica. 2014, vol.60, pp. 205-210.

GARDOLINSKI, José E. ; WYPYCH, Fernando; CANTAO, Maurício P.. Esfoliação e hidratação da caulinita após intercalação com ureia. Quím. Nova. 2001, vol.24, n.6, pp. 761767.

GARDOLINSKI, José E.; WYPYCH, Fernando; ZAMORA, Patricio P. Preparation and Characterization of a Kaolinite-1-methyl-2-Pyrrolidone Intercalation Compound. Journal of Colloid and Interface Science. 1999, vol.211, pp. 137-141.

GUERRA, Denis L.; AIROLDI, Claudio; DE SOUSA, Kaline S. Adsorption and thermodynamic studies of $\mathrm{Cu}(\mathrm{II})$ and $\mathrm{Zn}$ (II) on organofunctionalized-kaolinite. Applied Surface Science. 2008, Vol. 254, pp. 5157-5163.

PANDA, Achyut K.; MISHRA, B.G.; MISHRA, D.K.; SINGH, R.K. Effect of sulphuric acid treatment on the physico-chemical characteristics of kaolin clay. Colloids and Surfaces A: Physicochem. Eng. Aspects. 2010, vol.363, pp. 98-104.

\section{AGRADECIMENTOS}

Ao laboratório de mecânica da UTFPR campus Curitiba pelas análises de DRX, À Central de Análises da UTFPR/PB pelas análises de FT-IR e a UTFPR/PB pelo auxílio financeiro. 